\title{
Quantitative analysis of alterations in liver ultrastructure of rainbow trout Oncorhynchus mykiss after administration of the aquaculture antibacterials oxolinic acid and flumequine
}

\author{
Katerina A. Moutou ${ }^{1}$, Thomas Braunbeck ${ }^{2, *}{ }^{2}$ Dominic F. Houlihan ${ }^{1}$ \\ ${ }^{1}$ Department of Zoology, University of Aberdeen, Tillydrone Avenue, Aberdeen AB24 3TZ, Scotland, UK \\ ${ }^{2}$ Department of Zoology I, University of Heidelberg, Im Neuenheimer Feld 230, D-69120 Heidelberg, Germany
}

\begin{abstract}
The 4-quinolone antibacterials oxolinic acid and flumequine are routinely and successfully used in commercial aquaculture. In order to investigate the effects of these antibiotics on fish liver ultrastructure, rainbow trout were fed diets containing oxolinic acid or flumequine at concentrations of 1.0 and $1.2 \mathrm{~g} \mathrm{~kg}^{-1}$ food, respectively, at a ration of $1 \%$ body weight $\mathrm{d}^{-1}$ for $10 \mathrm{~d}$. Fish were sampled for examination on Days 1 and 10 after a return to normal diet and hepatic ultrastructural alterations were quantified by stereological analysis. Both drugs induced an almost 2.5 -fold increase in the volume of the rough endoplasmic reticulum, which displayed phenomena of dilation, vesiculation and fragmentation. Glycogen deposits were depleted to approximately $50 \%$ of their control volume accompanied by the formation of clusters of lipid droplets. Additional structural alterations included the intralysosomal accumulation of stacked membranes and the presence of elaborated myelin figures interspersed in the cytoplasm. No drug-specific responses were observed. In general, compensatory rather than degenerative changes followed the antibiotic administration. Further signs supporting a stimulation in the hepatocellular metabolic activity were mitochondrial hyperplasia after flumequine administration and high nuclear-cytoplasmic ratios in individuals treated with oxolinic acid
\end{abstract}

KEY WORDS: Antibiotics · Oxolinic acid · Flumequine - Rainbow trout · Liver - Ultrastructure

\section{INTRODUCTION}

Due to its central role in biotransformation of numerous compounds released into the aquatic environment, fish liver has received particular attention in toxicological investigations, and, indeed, it has been shown to react very sensitively to exposure to organic and inorganic pollutants (Braunbeck et al. 1987, 1990, Phillips et al. 1987). Efforts to evaluate hepatotoxicity in fish as an effect of toxic agents have been made principally through histological and cytological studies (Gingerich 1982, Meyers \& Hendricks 1985). An increasing number of chemicals have shown the potential to induce lesions in the liver of fish and many are capable of inducing ultrastructural changes in the

- Addressee for correspondence.

E-mail: braunbeck@urz.uni-heidelberg.de hepatocytes (Rojik et al. 1983, Hinton et al. 1987, 1988, Braunbeck et al. 1989, 1990, Braunbeck \& Völkl 1991, Arnold et al. 1995, 1996a, b, Oulmi et al. 1995). In many cases, these alterations in ultrastructure were strongly correlated with biochemical changes, predominantly in the activity of the cytochrome P450 monooxygenases (Lipsky et al. 1978, Klaunig et al. 1979, Schoor \& Couch 1979, Braunbeck \& Volkl 1991, 1993, Arnold et al. 1995).

Oxolinic acid and flumequine (Fig. 1) are members of the 4-quinolones, a family of systemic synthetic antibacterials, which interfere with the action of bacterial DNA gyrase by preventing the completion of the negative supercoiling of the bacterial chromosome (Smith 1985). They were introduced in fisheries chemotherapy in the early $70 \mathrm{~s}$, and, since then, they have been routinely and successfully used in commercial aquaculture for the control of furunculosis and red 


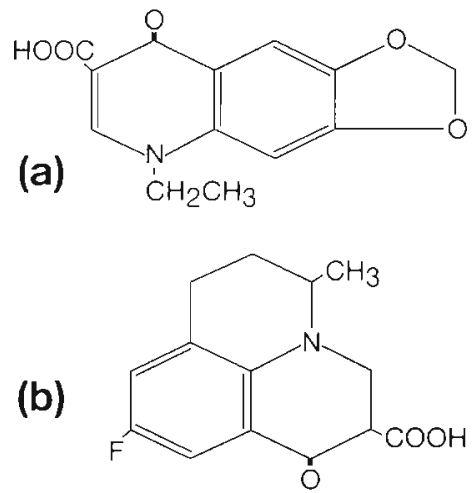

Fig. 1. Chemical structures of (a) oxolinic acid and (b) flumequine

mouth disease in trout (for review, see Alderman 1988). Unfortunately, no exact data for their usage in commercial aquaculture are available, since, unlike the situation in Norway, there are no central archives for such information. However, it has been estimated that, in the Scottish salmon farming industry alone, 12 to 15 tonnes of oxolinic acid are used per annum while the annual quantity of oxolinic acid used in Norwegian salmonid farming accounts for approximately $30 \%$ of the total amount of antibacterials used (Grave et al. 1990, Redshaw 1995).

Oxolinic acid and flumequine replaced conventional antibacterials due to the advantages of low toxicity, high efficacy in low doses, fast elimination and lack of plasmid-mediated resistance (Endo et al. 1973a, b, Barnes et al. 1991, Hustvedt et al. 1991a, b, c). However, in recent years, there has been increasing evidence of the development of bacterial resistance, lack of biodegradation following release in the water, persistence in sediments and as residues in flesh even after the maintenance of cooking temperatures for sustained durations, and, more recently, oxolinic acid was reported to induce benign Leydig cell tumours in rat testis (Samuelsen et al. 1994, Steffenak et al. 1994, Yamada et al. 1994, Hektoen et al. 1995).

The elimination of oxolinic acid in carp blood, liver, kidney and muscle was shown to be highly affected by the polychlorinated biphenyl (PCB)-inducible drugmetabolising enzymes (Oshima et al. 1994). Moreover, in a parallel communication, it could be demonstrated that both oxolinic acid and flumequine significantly induced cytochrome P4501A monooxygenase activities when orally administered to rainbow trout (Moutou et al. unpubl.). The present study was initiated, since immunocytochemical studies had shown that in rainbow trout hepatocytes cytochrome P4501A was localised on both rough and smooth endoplasmic reticulum (Lester et al. 1992, 1993), and oxolinic acid and flumequine were suspected to trigger a series of ultra- structural alterations in parallel to the biochemical changes observed (Moutou et al. unpubl.). In order to avoid the possibly subjective nature of electron micrographs, an attempt was made to quantify the ultrastructural effects by morphometric analysis (Segner \& Braunbeck 1990).

When administered orally (single dose of $5 \mathrm{mg} \mathrm{kg}$-1 body weight) to rainbow trout at water temperatures of 13 to $14^{\circ} \mathrm{C}$, oxolinic acid and flumequine are known to reach peak plasma concentrations as early as after the first $20 \mathrm{~h}$ (Kleinow et al. 1994, Sohlberg et al. 1994). As shown by measurement of ethoxyresorufin-O-deethylase, P450 monooxygenase activities displayed peaks on Days 1 (flumequine) and 10 (oxolinic acid) after the end of a $10 \mathrm{~d}$ administration (Moutou et al. unpubl.). Accordingly, sampling for cytological and morphometric analysis was conducted on Days 1 and 10 posttreatment, in order to examine possible alterations in the hepatocellular ultrastructure, when maximum body concentration of the drugs and highest activity of P450 monooxygenases were reached.

\section{MATERIALS AND METHODS}

Fish husbandry. Seventy-eight sexually immature rainbow trout Oncorhynchus mykiss $(218.9 \pm 4.64 \mathrm{~g})$ were obtained from the Almond Bank hatchery (Scotland, UK) and were randomly divided into 3 groups of 26 fish, respectively. During acclimation, $2 \mathrm{wk}$ prior to the start of the experiment, fish were fed a control diet (see below) once per day at a rate of $1 \%$ body weight $\mathrm{d}^{-1}$. All groups were hand-fed until no more than 2 to 3 pellets remained uneaten. Fish were held indoors in circular tanks (350 I) supplied with continuous flow of aerated fresh water at a rate of $401 \mathrm{~h}^{-1}$ and exposed to a $13 \mathrm{~h}$ light: $11 \mathrm{~h}$ dark photoperiod. Mean water temperature during the experiment was $14.2^{\circ} \mathrm{C}$ with a range from 13.8 to $15.8^{\circ} \mathrm{C}$. No mortalities occurred, and no external signs of alterations were seen.

Diet preparation. Control and medicated diets were prepared using a standard pelleted commercial trout diet (Ewos, Trout Starter, $2.4 \mathrm{~mm}$ diameter). To prepare the contral diet, pellets of the commercial food were powdered and re-pelleted to $4.5 \mathrm{~mm}$ diameter. For the preparation of the medicated diets, pellets of the commercial food were powdered and oxolinic acid or flumequine (Sigma Chemical Co.) in powder form were directly added to give concentrations of 1.0 and $1.2 \mathrm{mg} \mathrm{g}^{-1}$ wet weight food, respectively. After thorough mixing, both medicated diets were re-pelleted to a size similar to that of the control diet.

Treatment and sampling. Each of the 2 groups were fed a differently medicated diet each for $10 \mathrm{~d}$, a period used for antibiotic treatment in aquaculture; the third 
group served as control. On Days 1 and 10 after the last exposure to the antimicrobial diet, 4 fish of each group were sampled for histological analysis. Sampling was performed at midmorning to avoid diurnal variation, and individual body and liver weights were recorded. Between the sampling days, fish were fed on control diet.

Electron microscopy. Fish were killed by a blow to the head and the livers were rapidly excised, cut into $1 \mathrm{~mm}$ cubes and immersed for at least $48 \mathrm{~h}$ into $1.5 \%$ glutardialdehyde and $1.5 \%$ formaldehyde in $0.1 \mathrm{M}$ sodium phosphate buffer (pH 7.6) containing $2.5 \%$ polyvinylpyrrolidone (PVP). After rinsing in $0.1 \mathrm{M}$ sodium cacodylate buffer $(\mathrm{pH} 7.6)$, fixation was continued in $2.5 \%$ glutardialdehyde in $0.1 \mathrm{M}$ sodium cacodylate buffer ( $\mathrm{pH}$ 7.6) containing 4\% PVP and $0.05 \% \mathrm{CaCl}_{2}$ for $1 \mathrm{~h}$. After rinsing in cacodylate buffer, blocks were postfixed for $1 \mathrm{~h}$ with $1 \%$ osmium ferrocyanide (Karnovsky 1971). After washing in $0.1 \mathrm{M}$ cacodylate and $0.05 \mathrm{M}$ maleate buffers ( $\mathrm{pH}$ 5.2), tissues were stained en bloc with $1 \%$ uranyl acetate in maleate buffer overnight. Blocks were dehydrated in a graded series of ethanol and embedded in Spurr's medium (Spurr 1969). All fixation steps were conducted at $4^{\circ} \mathrm{C}$. Ultrathin sections of 60 to $80 \mathrm{~nm}$ thickness were stained with alkaline lead citrate (Reynolds 1963) for $1 \mathrm{~min}$ and examined in a Zeiss EM10 electron microscope.

Light microscopy. Sections of $0.5 \mu \mathrm{m}$ thickness were stained with methylene blue-Azur II (Richardson et al. 1960) and used for orientation. For visualisation of glycogen, semithin sections were incubated in an alkaline $1 \%$ solution of silver diamine for $90 \mathrm{~min}$ at $60^{\circ} \mathrm{C}$ (Singh 1964). After rinsing in distilled water, sections were mounted in Entellan and examined in a Leitz Aristoplan light microscope.

Cytochemistry. Peroxisomal activity of catalase was demonstrated with alkaline 3,3'-diaminobenzidine (DAB) according to Le Hir et al. (1979). Blocks fixed in glutardialdehyde were incubated in $10 \mathrm{mM}$ Teorell-
Stenhagen buffer ( $\mathrm{pH} 10)$ containing $5 \mathrm{mM}$ DAB and $0.5 \% \mathrm{H}_{2} \mathrm{O}_{2}$ for 90 min at $37^{\circ} \mathrm{C}$ using a shaking water bath. Subsequently, they were postfixed in osmium ferrocyanide and processed for electron microscopy as described above.

Stereological analysis. Multistage sampling and morphometrical evaluation were performed according to the principles of Weibel et al. (1969) and Weibel (1979). The primary sample consisted of 40 tissue blocks derived from 4 individuals. From each individual fish, 5 blocks were selected at random to represent the secondary sample. The tertiary sample consisted of micrographs recorded on the sections of the secondary sample.

Three different levels of morphometrical analysis were conducted according to Arnold et al. (1995, 1996a; Table 1). Volume densities $\left(V_{v}\right)$ were estimated by placing a lattice of test points (PT) on micrographs and determining the fraction $\left(\mathrm{P}_{i} / \mathrm{PT}\right)$ of these points enclosed within profiles of the structure investigated $\left(\mathrm{P}_{i}\right)$. At both levels, the hepatocyte was selected as reference space and test points falling on extracellular space (biliary tracts, sinusoids, endothelia, space of Disse, etc.) were subtracted from the total number of test points.

Numerical densities $\left(N_{v_{1}}\right)$ of the above hepatocellular structures within the test area were calculated according to the formula of Weibel et al. (1969), $N_{v,}=b^{-1}$ $N_{\mathrm{A}_{1}}{ }^{1.5} / V_{V_{1}}^{0.5}$, where $N_{A_{1}}$ is the number of actually counted particles divided by the test area, $V_{v_{1}}$ the volume density of the particle and $b$ the shape-dependent coefficient. The coefficient $b$ was assumed to be 1.38 for peroxisomes and 2.25 for mitochondria (Weibel et al. 1969). The numerical density $N_{v_{\text {nu }}}$ of nuclei was used to calculate the volume of hepatocytes according to the formula $V_{\text {hep }}=1 / N_{v_{\text {nu }}}$.

Surface density $\left(S_{v}\right)$ of the rough endoplasmic reticulum (RER) was calculated by using a test line system according to the ratio of the 2 -fold intersections $\left(\mathrm{I}_{i}\right)$ with RER cisternae and the total length of lines on the hepatocytes investigated (LT) (Williams 1977). The

Table 1 Levels of morphometrical analysis. PT total number of points; LT: total number of lines; $d$ : distance between points or total length of lines. RER: rough endoplasmic reticulum

\begin{tabular}{|c|c|c|c|c|}
\hline Magnification & $\begin{array}{c}\text { Test system } \\
\text { PT/LT } d(\mu \mathrm{m})\end{array}$ & $\begin{array}{l}\text { Numerical } \\
\text { density }\left(\mu \mathrm{m}^{3}\right)\end{array}$ & $\begin{array}{l}\text { rameters measured } \\
\text { Volume } \\
\text { density }\left(\mu \mathrm{m}^{3}\right)\end{array}$ & $\begin{array}{l}\text { Surface } \\
\text { density }\left(\mu \mathrm{m}^{3}\right)\end{array}$ \\
\hline $1410 \times($ semithin $)$ & $\begin{array}{l}\text { Square lattice } \\
330 \quad 7.092\end{array}$ & $\begin{array}{l}\text { Nuclei }\left(N_{v_{n u}}\right) \\
\text { Glycogen }\left(V_{v_{g l}}\right)\end{array}$ & Nuclei $\left(V_{v_{n u}}\right)$ & \\
\hline $18000 \times$ (ultrathin) & $\begin{array}{l}\text { Square lattice } \\
288 \quad 0.555 \\
\\
\text { Line system } \\
16\end{array}$ & $\begin{array}{l}\text { Mitochondria }\left(M_{v_{\mathrm{ml}}}\right) \\
\text { Peroxisomes }\left(N_{v_{p e}}\right) \\
\operatorname{RER}\left(V_{v_{\mathrm{RER}}}\right)\end{array}$ & $\begin{array}{l}\text { Mitochondria }\left(V_{v_{m i}}\right) \\
\text { Peroxisomes }\left(V_{v_{p e}}\right)\end{array}$ & $\operatorname{RER}\left(S_{v_{R E R}}\right)$ \\
\hline
\end{tabular}


surface of RER cisternae per hepatocyte was estimated as $S_{v} \times V_{\text {hep. }}$

Absolute numbers and volumes per hepatocyte were estimated as $N_{v} \times V_{\text {hep }}$ and $V_{v} \times V_{\text {hep }}$, respectively. Hepatocyte and nuclear diameters were estimated as the third root of the relevant volume assuming spherical shape of the particles.

Statistics. All means are given with standard errors. Arcsine transformation was used to normalise percentage and ratio data before analysis. One-way analysis of variance (ANOVA) and Scheffe's multiple comparison test were used to compare the effects on morphological parameters of different treatments and sampling days (Zar 1984). For all experiments, a $5 \%$ level of significance was chosen.

\section{RESULTS}

Incorporation of flumequine into the diet did not appear to affect mean daily food consumption; the entire ration was consumed during the medication period. On the contrary, fish fed the oxolinic acid diet showed signs of reduced appetite and consumption. Mean hepatosomatic indices on both sampling days
Table 2. Hepatosomatic index of control and antibiotic-treated rainbow trout on Days 1 and 10 of the recovery period. Means with the same letter are not significantly different from each other $(\mathrm{p}>0.05)$

\begin{tabular}{lll}
\hline Treatment & Day 1 & Day 10 \\
\hline Control & $1.52 \pm 0.25^{\mathrm{a}}$ & $1.03 \pm 0.06^{\mathrm{ab}}$ \\
Oxolinic acid & $1.43 \pm 0.59^{\mathrm{ab}}$ & $0.82 \pm 0.14^{\mathrm{b}}$ \\
Flumequine & $0.98 \pm 0.33^{\mathrm{ab}}$ & $0.87 \pm 0.09^{\mathrm{ab}}$ \\
& &
\end{tabular}

were lower in either antibiotic-treated fish, but not significantly different from controls. Overall mean hepatosomatic index was $1.10 \pm 0.08$ (Table 2 ).

\section{Controls}

No significant differences were found in the cytological characteristics between hepatocytes of control rainbow trout sampled on Days 1 and 10 after the end of medication. Thus, data recorded on both days were pooled to give one set of values for control morphological parameters. Hepatocytes of untreated rainbow trout presented the characteristic polarity and compartmentation described in detail previously (Hacking

Table 3. Morphometric parameters of control and antibiotic-treated rainbow trout on Days 1 and 10 of the recovery period. Means with the same letter across rows are not significantly different from each other $(p>0.05)$

\begin{tabular}{|c|c|c|c|c|c|}
\hline & \multirow{2}{*}{ Control } & \multicolumn{2}{|c|}{ Oxolinic acid } & \multicolumn{2}{|c|}{ Flumequine } \\
\hline & & Day 1 & Day 10 & Day 1 & Day 10 \\
\hline \multicolumn{6}{|l|}{ Hepatocyte } \\
\hline Volume $\left(\mu^{3}\right)^{3}$ & $2470.9 \pm 159.8^{a}$ & $2478.2 \pm 186.5^{a}$ & $1478.9 \pm 110.3^{b}$ & $1990.5 \pm 251.0^{a}$ & $1645.0 \pm 593.9^{a b}$ \\
\hline Diameter $(\mu \mathrm{m})$ & $16.7 \pm 0.4^{\mathrm{i}}$ & $16.8 \pm 0.4^{\mathrm{d}}$ & $14.1 \pm 0.4^{\mathrm{a}}$ & $15.5 \pm 0.6^{\mathrm{a}}$ & $15.5 \pm 0.8^{a}$ \\
\hline \multicolumn{6}{|l|}{ Nuclei } \\
\hline Volume $\left(\mu \mathrm{m}^{3}\right)$ & $138.4 \pm 7.4^{d}$ & $232.1 \pm 18.2^{\mathrm{b}}$ & $173.78 \pm 21.31^{a b}$ & $167.8 \pm 12.8^{\mathrm{ab}}$ & $210.8 \pm 23.9^{a b}$ \\
\hline Diameter ( $\mu \mathrm{m})$ & $6.4 \pm 0.1^{\mathrm{d}}$ & $7.60 \pm 0.21^{b}$ & $6.9 \pm 0.3^{a b}$ & $6.8 \pm 0.2^{a b}$ & $7.4 \pm 0.3^{\mathrm{ab}}$ \\
\hline Nuclear-cytoplasmic ratio & $0.06^{\mathrm{a}}$ & $0.10^{\mathrm{ab}}$ & $0.12^{\mathrm{b}}$ & $0.09^{\mathrm{ab}}$ & $0.11^{\mathrm{b}}$ \\
\hline Volume density ( $\left.\mathrm{um}^{3} / \mu \mathrm{m}^{3}\right)$ & $0.06 \pm 0.01^{\mathrm{a}}$ & $0.10 \pm 0.01^{\mathrm{ab}}$ & $0.12 \pm 0.01^{b}$ & $0.09 \pm 0.01^{\mathrm{ab}}$ & $0.11 \pm 0.01^{b}$ \\
\hline Numerical density $\left(\mu \mathrm{m}^{-3}\right)$ & $0.42 \pm 0.07^{d}$ & $0.42 \pm 0.04^{\mathrm{s}}$ & $0.69 \pm 0.05^{d}$ & $0.53 \pm 0.07^{\circ}$ & $0.54 \pm 0.08^{a}$ \\
\hline \multicolumn{6}{|l|}{ Mitochondria } \\
\hline Volume density $\left(\mu m^{3} / \mu m^{3}\right)$ & $0.08 \pm 0.01^{\mathrm{a}}$ & $0.08 \pm 0.01^{\mathrm{a}}$ & $0.08 \pm 0.01^{\mathrm{d}}$ & $0.08 \pm 0.01^{a}$ & $0.08 \pm 0.01^{\circ}$ \\
\hline Numerical density $\left(10^{9} / \mu \mathrm{m}^{3}\right)$ & $187.5 \pm 5.9^{4}$ & $227.0 \pm 28.1^{a b}$ & $271.8 \pm 48.1^{\mathrm{ab}}$ & $228.5 \pm 48.2^{\mathrm{ab}}$ & $396.8 \pm 55.7^{b}$ \\
\hline Volume per hepatocyte $\left(\mu^{3}\right)$ & $209.0 \pm 32.1^{d}$ & $207.5 \pm 21.6^{\alpha}$ & $121.9 \pm 21.7^{\mathrm{a}}$ & $154.5 \pm 5.5^{4}$ & $139.2 \pm 86.6^{\mathrm{d}}$ \\
\hline Number per hepatocyte & $462.4 \pm 34.6^{\circ}$ & $549.5 \pm 44.2^{a b}$ & $393.7 \pm 53.4^{\alpha}$ & $412.9 \pm 38.4^{19}$ & $736.9 \pm 21.2^{b}$ \\
\hline \multicolumn{6}{|l|}{ Peroxisomes } \\
\hline Volume density $\left(\mu^{3} / \mu m^{3}\right)$ & $0.014 \pm 0.005^{a}$ & $0.020 \pm 0.005^{\mathrm{a}}$ & $0.017 \pm 0.001^{\mathrm{a}}$ & $0.020 \pm 0.006^{\mathrm{a}}$ & $0.024 \pm 0.006^{4}$ \\
\hline Numerical density $\left(10^{9} / \mu^{3}\right)$ & $92.0 \pm 41.8^{\mathrm{a}}$ & $203.3 \pm 46.1^{\mathrm{a}}$ & $212.8 \pm 31.4^{a}$ & $118.2 \pm 30.9^{a}$ & $214.8 \pm 16.2^{4}$ \\
\hline Volume per hepatocyte $\left.\left(\mu^{3}\right)^{3}\right)$ & $34.3 \pm 11.8^{d}$ & $50.3 \pm 12.1^{\mathrm{a}}$ & $26.2 \pm 3.7^{\mathrm{d}}$ & $36.2 \pm 9.5^{\mathrm{d}}$ & $52.6 \pm 21.3^{a}$ \\
\hline Number per hepatocyte & $205.6 \pm 74.4^{a}$ & $480.4 \pm 69.4^{a}$ & $305.9 \pm 27.8^{\mathrm{a}}$ & $217.8 \pm 43.6^{\mathrm{d}}$ & $420.1 \pm 56.1^{\mathrm{a}}$ \\
\hline \multicolumn{6}{|l|}{ Rough endoplasmic reticulum } \\
\hline Volume density $\left(\mu \mathrm{m}^{3} / \mu \mathrm{m}^{3}\right)$ & $0.23 \pm 0.04^{\mathrm{a}}$ & $0.57 \pm 0.09^{b}$ & $0.54 \pm 0.03^{b}$ & $0.40 \pm 0.06^{\mathrm{ab}}$ & $0.56 \pm 0.03^{b}$ \\
\hline Surface density $\left(\mu \mathrm{m}^{2} / \mu \mathrm{m}^{3}\right)$ & $2.4 \pm 0.3^{a}$ & $4.1 \pm 0.4^{a}$ & $3.6 \pm 0.3^{a}$ & $4.1 \pm 0.4^{d}$ & $3.9 \pm 0.6^{a}$ \\
\hline Volume per hepatocyte $\left(\mu^{3}\right)$ & $582.0 \pm 107.3^{n}$ & $1419.7 \pm 139.8^{b}$ & $794.6 \pm 34.7^{\circ}$ & $750.1 \pm 22.6^{\circ}$ & $1115.5 \pm 206.0^{a b}$ \\
\hline Surface per hepatocyte $\left(\mu \mathrm{m}^{2}\right)$ & $5435.8 \pm 533.0^{a b}$ & $9095.0 \pm 1144.5^{\mathrm{c}}$ & $4672.6 \pm 515.8^{b}$ & $7052.0 \pm 541.4^{a b}$ & $6896.6 \pm 1229.95^{\text {ab }}$ \\
\hline \multicolumn{6}{|l|}{ Glycogen } \\
\hline Volume density $\left(\mu \mathrm{m}^{3} / \mu \mathrm{m}^{3}\right)$ & $0.52 \pm 0.04^{\mathrm{d}}$ & $0.14 \pm 0.01^{\mathrm{b}}$ & $0.26 \pm 0.05^{b}$ & $0.23 \pm 0.04^{b}$ & $0.27 \pm 0.01^{b}$ \\
\hline Volume per hepatocyte $\left(\mu \mathrm{m}^{3}\right)$ & $1290.5 \pm 125.81^{\circ}$ & $361.08 \pm 49.64^{b}$ & $381.55 \pm 92.27^{b}$ & $493.46 \pm 145.64^{b}$ & $539.75 \pm 11.0 .90^{b}$ \\
\hline
\end{tabular}


et al. 1977. Hampton et al. 1985, Braunbeck et al 1990). Mean diameter of hepatocytes was $16.74 \pm 0.38 \mu \mathrm{m}$, and their volume ranged from 2150 to $2790 \mu \mathrm{m}^{3}$ (Table 3) Nuclel were of spherical shape and characterised by slightly eccentric nucleoli and little, randomly scattered heterochromatin (Fig 2) Extended glycogen flelds were located in the cell periphery, representing more than $50 \%$ of the cell volume, and were clearly separated from organelle-contaning pernnuclear and periblliary areas (Figs. $2 \& 3$ ).

Stacks of parallel cisternae of RER interspersed with mitochondria covered pernuclear areas (Table 3 , Fig 2). Each hepatocyte contaned about 460 mitochondria (Table 3) They presented polycristae matrices rarely containing intramitochondrial granules and, as a whole, accounted for almost $8.5 \%$ of the hepatocyte volume (Fig. 3). Peroxisomes were found in close association with mitochondria, but were usually located at the outer border of the RER envelope. One hepatocyte contained about 200 small spherical peroxisomes with a mean volume $0.17 \pm 0.08 \mu^{3}$ (Table 3 . Fig 2)

Smooth endoplasmic reticulum (SER) was minute and restricted to peribiliary areas together with lysosomal elements of heterogenous matnx as well as few Golgı fields of 3 to 5 cisternae budding off numerous vesicles full of VLDL (Very Low Density Lipoprotein) granules.

\section{Oxolinic acid administration}

An overview of cytopathological alterations in fish treated with antıblotics is given in Table 4 On Day 1

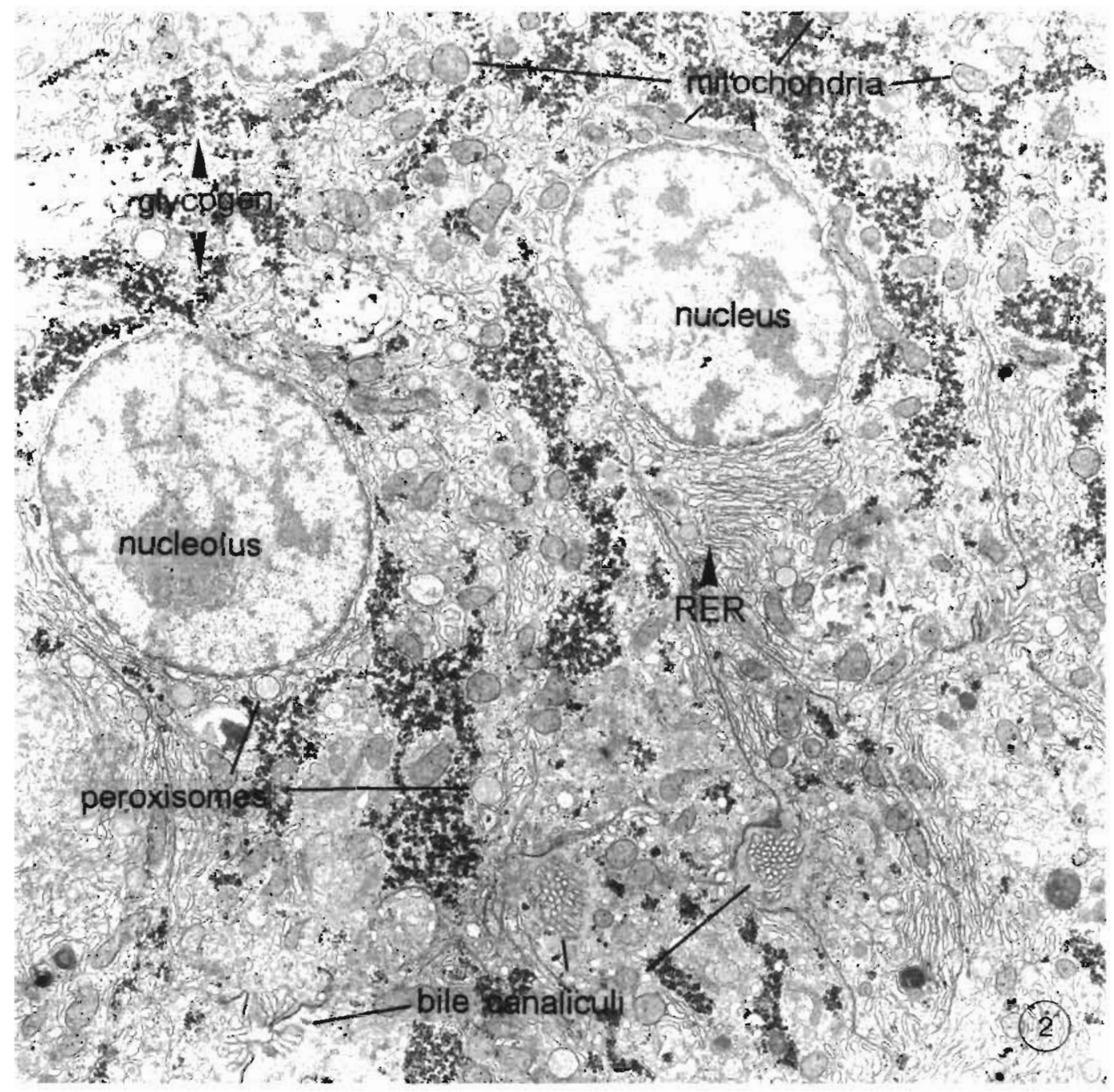

Fig. 2. Oncorhynchus mykiss Hepatocytes of control rambow trout were characterised by a central nucleus surrounded by stacks of rough endoplasmic reticulum (RER) interspersed with mitochondria and extensive glycogen fields at the periphery Golgi fields, smooth endoplasmic reticulum and lysosomes were located in the peribiliary areas $\times 5000$ 

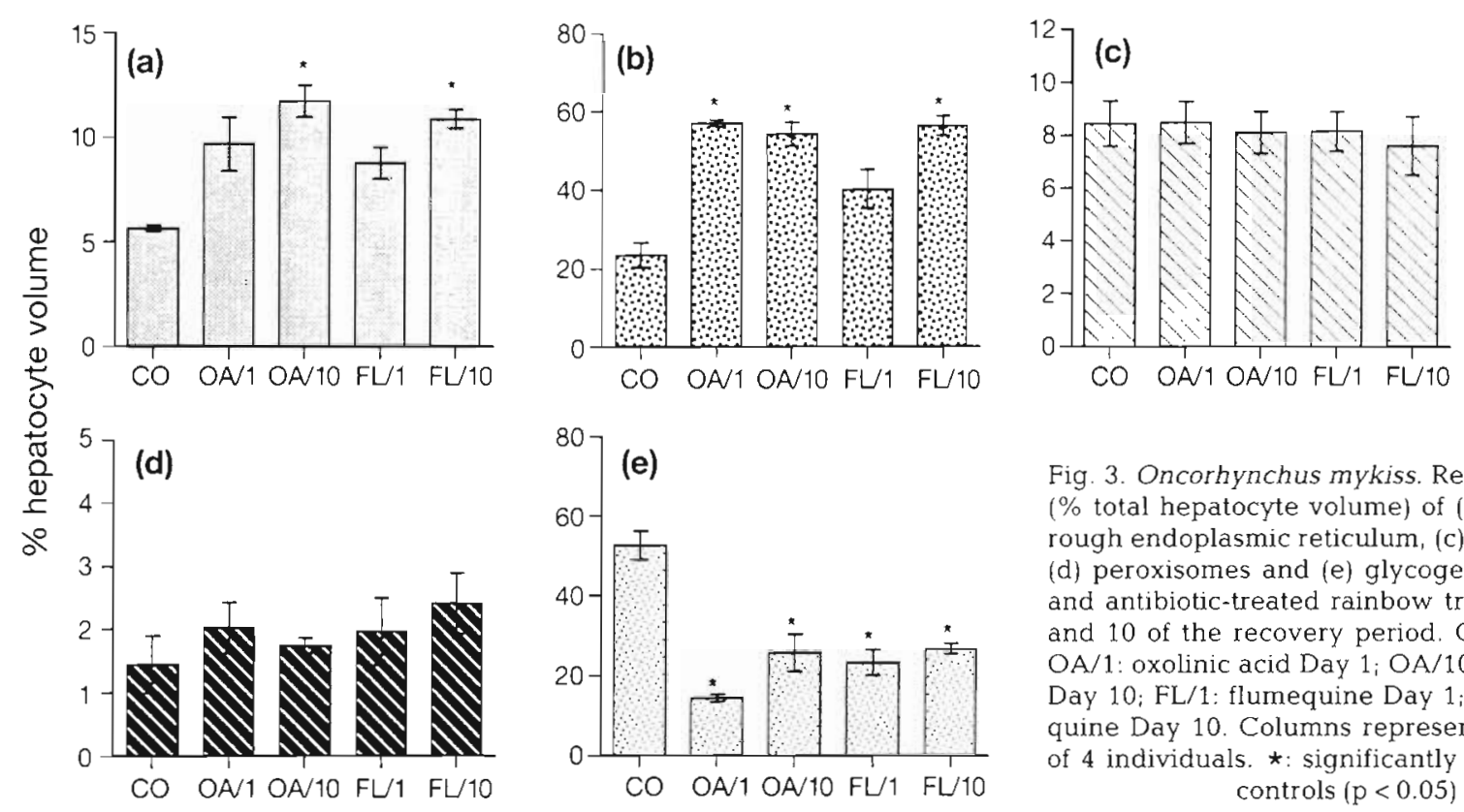

Fig. 3. Oncorhynchus mykiss. Relative volumes
(\% total hepatocyte volume) of (a) nucleus, (b)
rough endoplasmic reticulum, (c) mitochondria,
(d) peroxisomes and (e) glycogen in untreated
and antibiotic-treated rainbow trout on Days 1
and 10 of the recovery period. CO: untreated;
OA 1 : oxolinic acid Day 1 ; OA/10: oxolinic acid
Day 10; FL/1: flumequine Day 1 ; FL/10: flume-
quine Day 10 . Columns represent means $\pm \mathrm{SE}$
of 4 individuals. $\star$ : significantly different from
controls $(\mathrm{p}<0.05)$

post-treatment, no significant effects of oxolinic acid on mean hepatocyte size were found (Table 3). Nuclear volume and diameter, on the other hand, were significantly higher than in controls, with the nucleus accounting for $9.67 \%$ of the total hepatocellular volume (Table 3, Fig. 3). In addition, atypical nuclear profiles were frequently observed (Fig. 4). The most prominent cytoplasmic alterations, however, were observed in the RER and accompanied by a disorganisation of the cytoplasm (Fig. 4). A significant, almost 2.5-fold increase in the volume density of RER was found, but surprisingly, the surface density did not increase significantly (Table 3). Thus, the volume increase appeared to be mainly due to changes of matrix components rather than membrane constituents. Indeed, RER cisternae appeared to be strongly dilated and vesiculated (Figs. \& \& 5), occupying almost the entire cytoplasm and accounting for $57.12 \%$ of the hepatocellular volume (Figs. $3 \& 4$ ). No significant changes were found in either the number or the relative volume of mitochondria or peroxisomes (Table 3, Fig. 3). On the other hand, well-developed lysosomes and Golgi fields were more abundant compared with controls, with the latter exhibiting degenerative characteristics (Fig. 5). Glycogen fields were significantly depleted to $25 \%$ of their control size (Table 3, Fig. 3), with numerous glycogenosomes, in parallel with prominent accumulation of lipid droplets (Fig. 6).

On Day 10, the mean hepatocellular volume was significantly decreased, whereas nuclear dimensions were still larger, but not significantly different from controls (Table 3). Yet, a combination of smaller hepatocyte and larger nucleus resulted in a significantly higher nuclear volume density $(11.7 \%$ vs $5.63 \%$ in controls) and nuclear-cytoplasmic ratio (Table 3, Fig. 3). The volume density of RER reached the same levels as on Day 1 after the end of the medication. However, the volume of RER per hepatocyte was not significantly different from controls, due to a smaller reference volume (Table 3). Even $10 \mathrm{~d}$ after the end of oxolinic acid medication, phenomena of vesiculation and dilation were still evident, frequently accompanied by dilated nuclear envelopes (Figs. 6-8). The shift to the storage materials remained unaltered. Glycogen fields were still significantly depleted compared with controls, and glycogenosomes as well as lipid droplets were very frequent, in addition to intralysosomal accumulations of stacked membranes and numerous myelin whorls (Table 3, Figs, 3, 7, $9 \& 10$ ).

Figs. 4 to 6. Oncorhynchus mykiss. On Day 1 following oxolinic acid administration, a complete lack of cytoplasmic compartmentation (cf. Braunbeck et al. 1987) and prominent changes in rough endoplasmic reticulum (RER) including phenomena of dilation and vesiculation were evident (Figs. 4 \& 5). Atypical nuclear profiles were often present (Fig. 4 ; $*$ ) in parallel with welldeveloped lysosomes (Fig. $5 ; *$ ) and degeneration of Golgi fields (Fig. 5; arrowheads). Glycogen fields were severely depleted and replaced by lipid droplets (Fig. 6 ; *). Fig. 4: ×5000; Fig. 5: $\times 11700 ;$ Fig. $6: \times 10000$ 


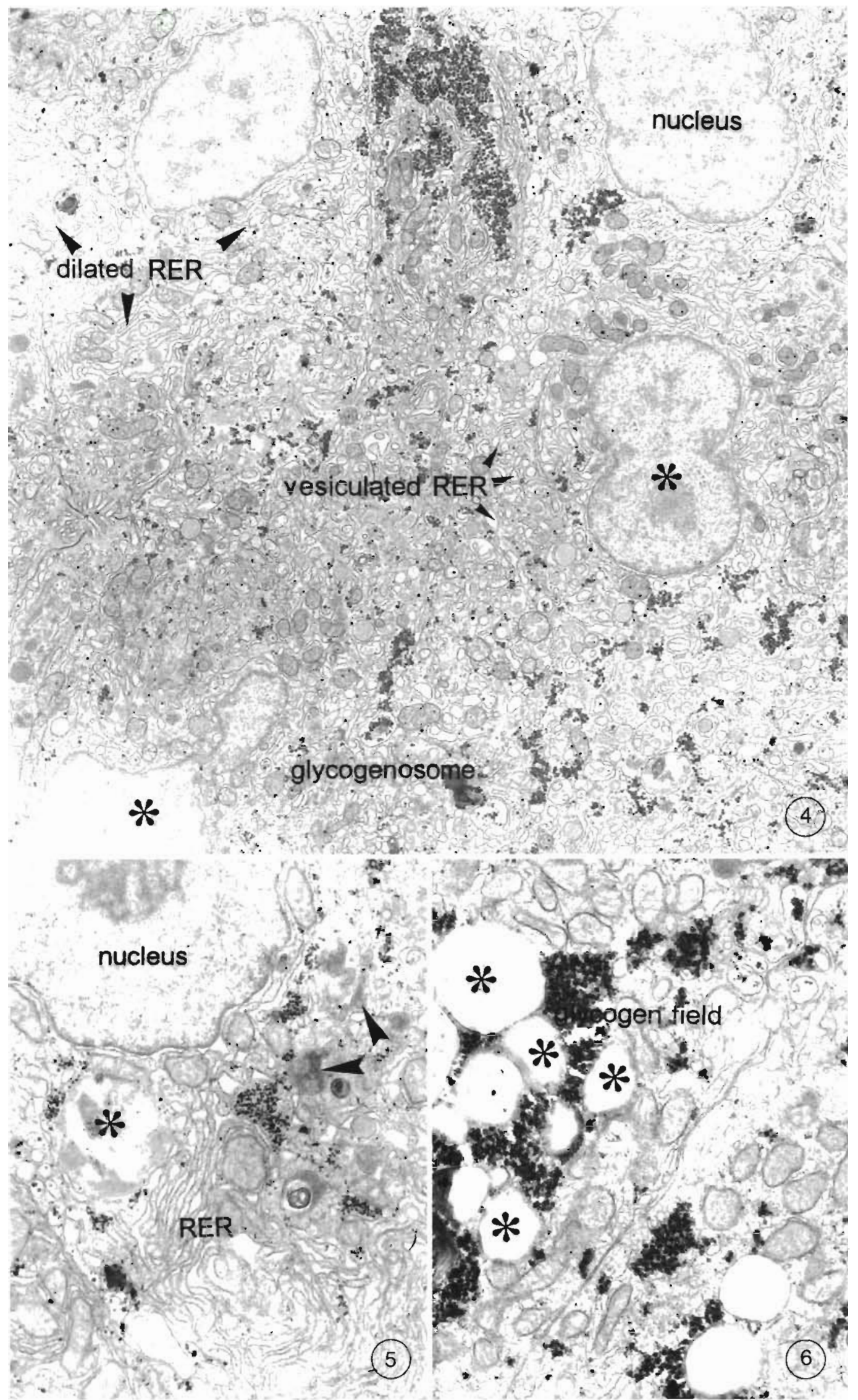


Table 4. Oncorhynchus mykiss. Cytopathological alterations induced in the liver of rainbow trout 1 and $10 \mathrm{~d}$ after termination of a $10 \mathrm{~d}$ period of medication with the antibiotics oxolinic acid or flumequine. Data are given as means from 4 individuals per treatment. For quantitative data see Table 3

$\begin{aligned} & \text { Oxolinic acid } \\ & \text { Day } 1 \text { Day } 10\end{aligned}$ Day 1 Day 10
Organisation of liver parenchyma
Interindividual variability of parenchyma
Disturbance of compartmentation
Relative decrease in cell size
Nuclei
Increase in nuclear volume
Occurrence of atypical nuclear profiles
Dilation of nuclear envelope
Mitochondria
Increased heterogeneity
Proliferation of small mitochondria
Relative increase in volume
Reduction in size of individual mitochondria
Rough endoplasmic reticulum
Increased heterogeneity
Relative increase in volume
Absolute increase in volume
Fragmentation of cisternae
Dilation of cisternae
Vesiculation of cisternae
Transformation of cisternae into myelin bodies
Golgi fields
Increased heterogeneity
Proliferation
Degeneration of Golgi cisternae
Lysosomal elements
Proliferation
Phospholipidosis
Myelinated bodies
Induction of multivesicular bodies
Induction of glycogenosomes
Storage materials
Increase of lipid deposits
Formation of lipid clusters
Decrease in glycogen stores
Induction of glycogenosomes

cantly higher nuclear-cytoplasmic ratio (Table 3, Fig 3).

Disturbance of the characteristic compartmentation was observed and it was accompanied by great inter-individual variability of the hepatocytes. Alterations in the RER were moderate compared with those after oxolinic acid administration. Relative volume was significantly increased on both Days 1 and 10 , whereas volume density was only significantly elevated on Day 10 post-treatment (Table 3, Fig. 3). Phenomena of dilation, fragmentation and vesiculation of the cisternae were very strong on both days, frequently associated with dilated nuclear envelopes (Fig. 11).

Ten days after the end of the medication, a significant increase in absolute number and numerical density of mitochondria was found (Table 3). However, mitochondrial absolute and relative volume remained unchanged, indicating that a rapid proliferation of small mitochondria could have taken place, which resulted in double the number of organelles, which, however, were half the size compared with controls. In addition, lysosomal compartment showed pronounced proliferation, including multivesicular bodies and numerous well-developed lysosomes with myelin-like stacks of membranous material, probably indicating induction of phospholipidosis. Simultaneously, high numbers of myelinated whorls were found within the severely depleted glycogen fields.

\section{Flumequine administration}

Flumequine administration resulted in decreased hepatocellular volume and diameter on both days tested, and in increased nuclear volume and diameter, without significant differences from controls, however. On Day 10 after the end of the medication, nuclear volume density and relative nuclear volume were significantly elevated over controls, due to a signifi- sometimes in close structural association with lipid droplets.

Following flumequine administration, hepatocellular storage materials were affected to almost the same extent as after oxolinic acid administration (Table 3 ). Absolute and relative volumes of glycogen were limited to half of their control values, whereas a high number of hepatocytes displayed numerous clusters of lipid droplets (Fig. 3).

Figs 7 to 10 . Oncorhynchus mykiss. On Day 10 post-treatment with oxolinic acid, disturbance of cytoplasmic compartmentation and changes in the rough endoplasmic reticulum (RER) were the predominant alterations in hepatocellular ultrastructure (Figs. $?$ \& 8). In many cases, the nuclear envelope appeared strongly dılated (Fig. 8). Lipid droplets (Fig. 7; $\star$ ) and glycogenosomes (Fig. 9; arrowheads) were abundant together with elaborated structures of myelin (Figs. $7 \& 10$ ). Fig. 7: $\times 4$ 100; Fig. 8: $\times 5000 ;$ Fig. 9: $\times 5000$; Fig. 10: $\times 6000$ 


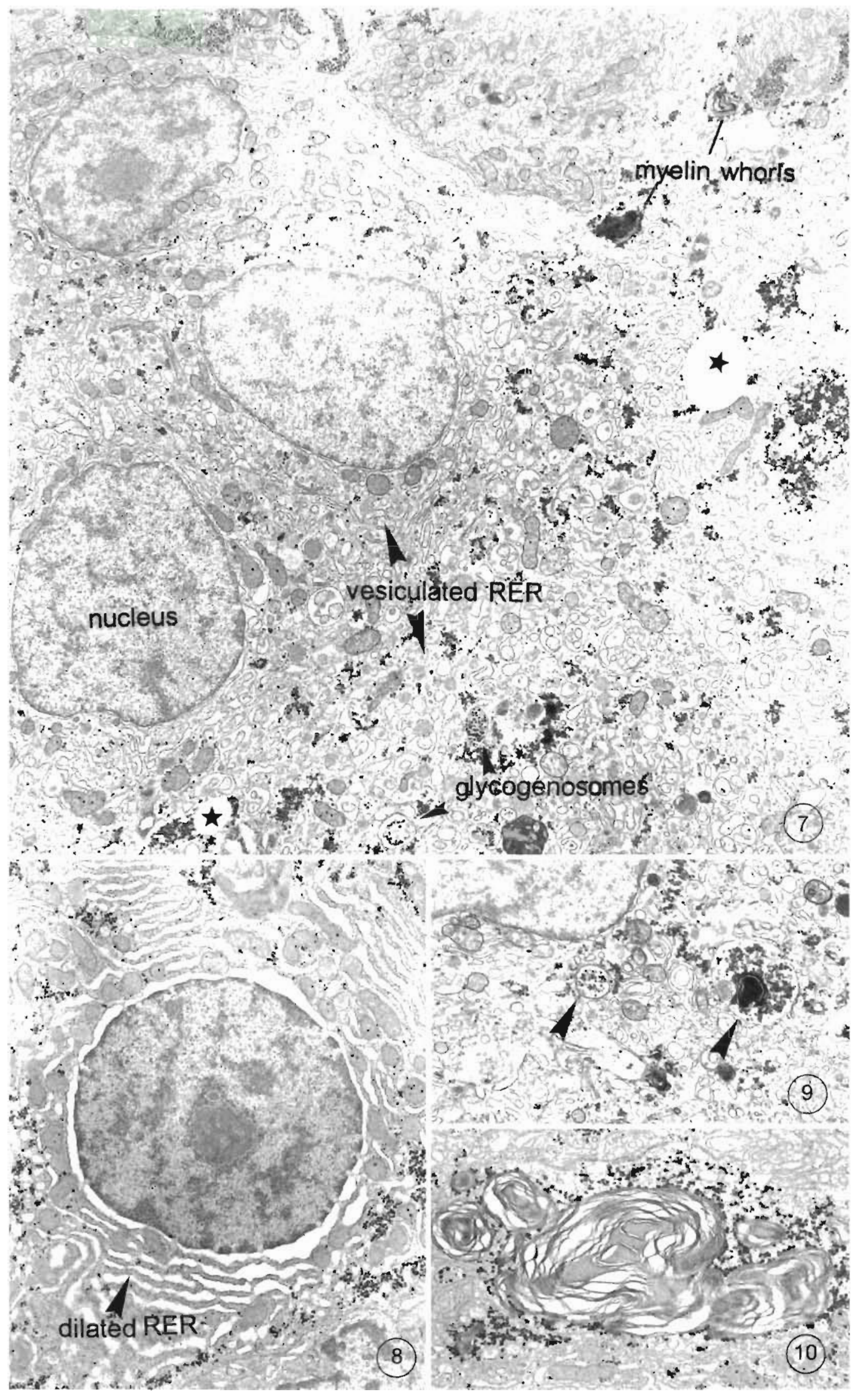




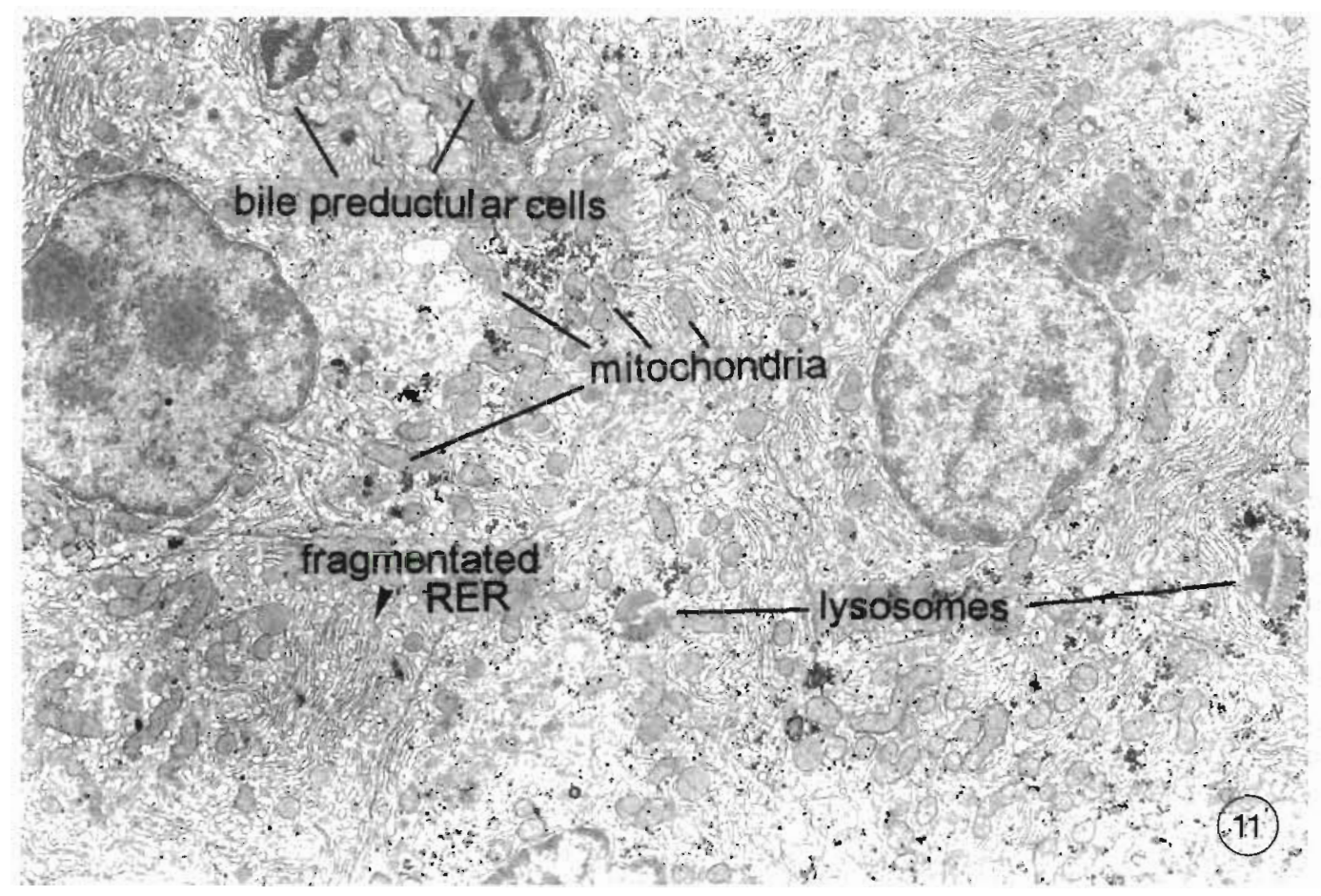

Fig. 11 Oncorhynchus mykiss. Fragmentation and vesiculation of the rough endoplasmic reticulum (RER) cisternae and severe depletion of glycogen deposits were the most prominent hepatocellular changes on both Days 1 and 10 post-treatment with flumequine (Day $10 ; \times 5000$ )

\section{DISCUSSION}

In stereological practice, only a minute tıssue fraction can be examined at the final stage of micrographs (Arnold et al. 1995). In order to guarantee for representative data collection, random multistage sampling procedures at different magnifications have been established. These procedures also ensure that the micrographs used for analysis meet 2 requirements: They are large enough to include a representative sample of the structures under examination, and they provide sufficlent resolution for precise recognition of the structures under investigation (Weibel et al. 1969) Stereology has been applied to quantify the effects of various xenobiotics in fish hepatocytes, and the levels of magnification employed in the present study were in accordance to those of previous studies (Peute et al. 1985, Segner \& Braunbeck 1990, Segner \& Witt 1990, Braunbeck \& Segner 1992, Arnold et al. 1995, 1996a, b).

In the present study. most prominent alterations were found in the RER. which displayed dilation, fragmentation and vesiculation of the cisternae. Since the endoplasmuc reticulum plays a major role in the detoxification of lipid-soluble compounds, it usually reacts very sensitively to exposure to various toxicants (De la Iglesia et al. 1982, Rez 1986). Proliferation of RER, for example, was evident in hepatocytes of rain- bow trout after chronic adminıstration of Aroclor 1254 (Hacking et al. 1977), in mullet Mugl cephalus following a single injection of 3-methyl cholanthrene (Schoor \& Couch 1979), in channel catfish Ictalurus punctatus after PCB administration (Lipsky et al. 1978) as well as in another catfish species, Tandanus tandanus, after exposure to endosulfan (Nowak 1996)

Likewise, in mammals, alterations in the endoplasmic retıculum have of ten been strongly correlated with drug administration. Both non-specific and specific changes in the SER of rat hepatocytes evident after administration of phenobarbital (PB), chlordane, benzo(a)pyrene $[\mathrm{B}(\mathrm{a}) \mathrm{P}]$ and 3-methylcholanthrene (3-MC) were mainly attributed to a stimulation of microsomal drug metabolism (Fouts \& Rogers 1965) In PB-treated rats and hamsters, SER hypertrophy has been regarded as an adaptive response (drug tolerance), by means of which an animal develops an enhanced ability to handle doses of drugs which would be fatal to normal animals. SER proliferation in mammalian hepatocytes is now regarded as the morphological expression of drug-induced enzyme production in the liver, with the expanded SER providing the surface for interaction of drugs and enzymes (reviewed by Phillıps et al. 1987. Ghadially 1988). In raınbow trout liver, however, immunocytochemical techniques localısed the mucrosomal monooxygenase system re- 
sponsible for the drug biotransformation in the RER in addition to the SER (Lester et al. 1992, 1993). Therefore, drugs with effects on the microsomal monooxygenase system would more likely induce changes in both RER and SER in fish hepatocytes.

Dilation and vesiculation of the RER cisternae are generally thought to be a result of enhanced storage of proteins within the cisternae (Ghadially 1988). It has also been suggested that dilation of the endoplasmic reticulum represents an early acute change resulting from inhibitory effects of a toxicant on protein synthesis with inhibition of incorporation of amino acids into liver proteins (Magee 1966). In fish hepatocytes, dilation and vesiculation of the RER cisternae were reported even in cases with no significant increase in the amount of the hepatocellular endoplasmic reticulum. Dilation, vesiculation and transformation of $R E R$ into concentric bodies were reported in hepatocytes of flounder Platichthys flesus contaminated with $\mathrm{Hg}$, HCB and PCBs (Köhler 1989, 1990), and in hepatocytes of rainbow trout after long-term exposure to sublethal concentrations of linuron (Oulmi et al. 1995) and disulfoton (Arnold et al. 1996b).

Nuclear-cytoplasmic ratios and relative nuclear volumes were significantly higher in antibiotic-treated individuals $10 \mathrm{~d}$ after the end of medication. In addition, atypical nuclear profiles were apparent in individuals administered oxolinic acid. Alterations in the volume and shape of the nucleus have often been regarded as signs of increased metabolic activity and may be of pathological origin. Bizarre nuclear profiles (nuclear atypia) or other changes including separation of nuclear components in fish hepatocytes were the result of exposure to various toxicants (Hacking et al. 1977, Lipsky et al. 1978, Klaunig et al. 1979, Braunbeck et al. 1989, 1990, Braunbeck \& Völkl 1991, Oulmi et al. 1995)

In many cases, nuclear changes in fish were combined with an increase in the number and heterogeneity of mitochondria (Braunbeck et al. 1990, Braunbeck \& Völkl 1991, Oulmi et al. 1995). In flumequine-treated individuals, the increased relative nuclear volume on Day 10 of the recovery period was also accompanied by a hyperplasia of mitochondria. It is widely held that there is a positive correlation between the metabolic activity of a tissue and the number and size of mitochondria, and hypertrophy/hyperplasia of the mitochondria is characteristic of tissues with increased functional demands (Dessouky 1968, Pelosi \& Agliati 1968, Zak \& Rabinowitz 1973). Since, in the present study, only numerical density and number of mitochondria per hepatocyte doubled, whereas total volume remained constant, the net increase in membrane surface area may be assumed to compensate for elevated respiratory demands.
The drastic shift in hepatocellular storage materials after antibiotic exposure could be another compensatory response of the cell to increased glycolytic activity to meet the energy demands imposed by enhanced metabolic activity (cf. Hanke et al. 1983, Gluth \& Hanke 1985, Braunbeck \& Völkl 1991, 1993) In the present experiment, elevated metabolic activity could not only be documented in terms of morphological alterations, but also as a stimulation of phase I biotransformation (Moutou et al. unpubl.). Severe depletion in glycogen amounts was often observed in fish as the result of various stress factors such as starvation, intoxication by pesticides, changes in temperature, inanition and sexual maturity (for literature, see Braunbeck et al. 1987 and Braunbeck \& Völkl 1993), whereas a shift from glycogen to lipid has frequently occured in livers of fasted animals, which, after glycogen depletion, shift to utilisation of lipids (Yamamoto \& Egami 1974, Hanke et al. 1983, Gluth \& Hanke 1985, Braunbeck et al. 1987, Ghadially 1988).

An interesting feature in antibiotic-treated fish was the presence of lipids in structural association with damaged membranes. In hepatocytes, lipid clusters were frequently found in close association with mitochondria, possibly due to the special enzyme contents of mitochondria (fatty acid oxidases) responsible for the metabolism of triglycerides (Palade \& Schidlowsky 1958), and membranous whorls in the vicinity of lipid droplets could represent degenerated mitochondria. However, the presence of myelin figures was very prominent in the entire cytoplasm of all the antibiotictreated fish. Since they represent a common feature in fish hepatocytes exposed to a variety of chemicals, the explanations proposed were that they may indicate a disturbance in lipid metabolism or membrane damage or even act as vehicles for hepatocyte detoxification accumulating and expelling the toxicant from the cell (Jonsson et al. 1981, Trump et al. 1983, Couch 1993). On the contrary, the intralysosomal accumulation of myelin figures was rather a degenerative than an adaptive response, as the overt increase in the lysosomal compartment containing cellular membrane-like material (phospholipidosis; Phillips et al. 1987) suggests an immediate decomposition of membrane structures containing excess phospholipid components as a response to antibiotic administration

Drug concentrations used in this study were in accordance with those employed in commercial fish farms and, in general, there was no morphological indication of drug-specific hepatocellular change after the administration of either oxolinic acid or flumequine. Thus, although intralysosomal accumulation of stacked membranes was seen as a degenerative phenomenon, which in some cases coincided with atrophic changes, destruction and disappearance of Golgi elements, the 
increase in the nuclear-cytoplasmic ratio in combination with dilation of the RER cisternae and hyperplasia of mitochondria more likely represented adaptive responses of the hepatocyte to higher metabolic demand and biotransformation. The lack of any macroscopical signs of degenerative pathology further supports the adaptive nature of the above morphological changes, which, however, did not appear to be reversible even $10 \mathrm{~d}$ after the end of medication.

With regard to current European Community legislation, the sensitivity of fish liver to oxolinic acid and flumequine can be of great importance for establishing maximum residue limits for antibiotics registered for use in aquaculture (Commission of the European Communities 1991). In order to be able to set maximum residue levels for use of a drug, among other things, data on drug biotransformation in target animals are required, and environmental impact assessments including tests examining the fate of the drug in the aquatic environment and its toxicity must be made. Alterations in hepatic ultrastructure as a result of drug administration as observed in this study imply that fish liver-especially if structural studies are coupled to functional investigations - may serve as a sensitive bioindicator for the toxicity of sublethal concentrations of aquaculture antibacterial agents.

Acknowledgements. The authors thank Mrs G. Adams and Mr T Berbner for excellent technical assistance as well as Drs Y Oulmi and H. Arnold for their comments on the preparation of the manuscript. The financial support by the Greek Scholarship Foundation (KAM) is gratefully acknowledged.

\section{LITERATURE CITED}

Alderman DJ (1988) Fisheries chemotherapy: a review. In: Muir JF, Roberts RJ (eds) Recent advances in aquaculture, Vol. 3. Timber Press, Portland, Oregon, p 1-61

Arnold H. Pluta HP, Braunbeck T (1995) Simultaneous exposure of fish to endosulfan and disulfoton in vivo: ultrastructural, stereological and biochemical reactions in hepatocytes of male rainbow trout (Oncorhynchus mykiss). Aquat Toxicol 33:17-43

Arnold H, Pluta HP, Braunbeck T (1996a) Cytological alterations in the liver of rainbow trout (Oncorhynchus mykiss) after prolonged exposure to water-borne endosulfan. Dis Aquat Org 25:39-52

Arnold $H$, Pluta HP, Braunbeck T (1996b) Sublethal effects of prolonged exposure to disulfoton in rainbow trout (Oncorhynchus mykiss): cytological alterations in the liver by a potent acetylcholinesterase inhibitor. Ecotoxicol Environ Saf 34:43-55

Barnes AC, Lewin CS, Hastings TS, Amyes SGB (1991) In vitro susceptibility of the fish pathogen Aeromonas salmonicida to flumequine. Antimicrob Agents Chemother $35: 2634-2635$

Braunbeck T (1994) Detection of environmentally relevant pesticide concentrations using cytological parameters: pesticide specificity in the reaction of rainbow trout liver?
In: Müller R, Lloyd R (eds) Sublethal and chronic effects of pollutants on freshwater fish. Blackwell, Oxford, p 15-29

Braumbeck T, Gorgas K, Storch V, Völkl A (1987) Ultrastructure of hepatocytes in golden ide (Leuciscus idus melanotus L., Cyprinidae: Teleostei) during thermal adaptation. Anat Embryol 175:303-313

Braunbeck T, Segner H (1992) Preexposure temperature acclimation and diet as modifying factors of the tolerance of golden ide (Leuciscus idus melanotus) to short-term exposure to 4-chloroaniline. Ecotoxicol Environ Saf 24:72-94

Braunbeck T, Storch V, Bresch H (1990) Species-specific reaction of liver ultrastructure of zebra fish (Brachydanio rerio) and trout (Salmo gairdnen) after prolonged exposure to 4-chloroaniline. Arch Environ Contam Toxicol 19:405-418

Braunbeck T, Storch V, Nagel R (1989) Sex-specific reaction of liver ultrastructure in zebra fish (Brachydanio rerio) after prolonged sublethal exposure to 4-nitrophenol. Aquat Toxicol 14:185-202

Braunbeck T, Völkl A (1991) Induction of biotransformation in the liver of eel (Anguilla anguilla L.) by sublethal exposure to dinitro-o-cresol: an ultrastructural and biochemical study. Ecotoxicol Environ Saf 21:109-127

Braunbeck T, Völkl A (1993) Toxicant-induced cytological alterations in fish liver as biomarkers of environmental pollution? A case study on hepatocellular effects of dinitro-o-cresol in golden ide (Leuciscus idus melanotus). In: Braunbeck T, Hanke W, Segner H (eds) Fish ecotoxicology and ecophysiology. $\mathrm{VCH}$, Weinheim, p 55-80

Commission of the European Communities (1991) The rules governing medicinal products in the European Community, Vol. VI, Establishment by the European Community of maximum residue limits (MRLs) for residues of veterinary medicinal products in foodstuffs of animal origin. Office for Official Publications of the European Communities, Luxembourg

Couch JA (1993) Light and electron microscopical comparisons of normal hepatocytes and neoplastic hepatocytes of well-differentiated hepatocellular carcinomas in a teleost fish. Dis Aquat Org 16:1-14

De la Iglesia FA, Sturgess JM, Feuer G (1982) New approaches for the assessment of hepatotoxicity by means of quantitative functional-morphological interrelationships. In: Plaa GL, Hewitt WR (eds) Toxicology of the liver. Raven Press, New York, p 47-102

Dessouky DA (1968) Electron microscopy studies of the myometrium of the guinea pig. Am J Obstet Gynecol 100 $30-41$

Endo $T$, Ogishima $K$, Hayasaka $H$, Kaneko $S$, Ohshima S (1973a) Application of oxolinic acid as a chemotherapeutic agent against infectious diseases in fishes - I. Antibacterial activity, chemotherapeutic effects and pharmacokinetics of oxolinic acid in fishes. Bull Jpn Soc Sci Fish 39 : $165-171$

Endo T, Sakuma M, Tanaka H, Ogishima K, Нага T, Ohshima S, Sato Y (1973b) Application of oxolinic acid as a chemotherapeutic agent against infectious diseases in fishes - II Explanation of chemotherapeutic effects by whole body autobacteriography. Bull Jpn Soc Sci Fish 39:173-177

Fouts JR, Rogers LA (1965) Morphological changes in the liver accompanying stimulation of microsomal drug metabolizing activity by phenobarbital, chlordane, benzo[a]pyrene or methylcholanthrene in rats. J Pharmacol Exp Ther 147:112

Ghadially FN (1988) Ultrastructural pathology of the cell and matrix, Vols I-II, 3rd edn. Butterworths, London

Gingerich WH (1982) Hepatic toxicology of fishes. In: Weber LJ (ed) Aquatic toxicology. Raven Press, New York, p 55-105 
Gluth G, Hanke W (1985) A comparison of physiological changes in carp, Cyprinus carpio, induced by several pollutants at sublethal concentrations. Ecotoxicol Environ Saf 9:179-188

Grave K, Engelstad M, Soli NE, Hastein T (1990) Utilization of antibacterial drugs in salmonid farming in Norway during 1980-1988. Aquaculture 86:347-358

Hacking MA, Budd J, Hodson K (1977) The ultrastucture of the liver of the rainbow trout: normal structure and modifications after chronic administration of a polychlorinated biphenyl Aroclor 1254. Can J Zool 56:477-491

Hampton JA, McCuskey PA, McCuskey RS, Hinton DE (1985) Functional units in rainbow trout (Salmo gairdneri) liver: I. Arrangement and histochemical properties of hepatocytes. Anat Rec 213:166-175

Hanke W, Gluth G, Bubel H, Müller R (1983) Physiological changes in carps induced by pollution. Ecotoxicol Environ Saf 7:229-241

Hektoen H, Berge JA, Hormazabal V, Yndestad M (1995) Persistence of antibacterial agents in marine sediments. Aquaculture 133:175-184

Hinton DE, Couch JA, Teh SJ, Courtney LA (1988) Cytological changes during progression of neoplasia in selected fish species. Aquat Toxicol 11:77-112

Hinton DE, Lantz RC, Hampton JA, McCuskey PR, McCuskey RS (1987) Normal versus abnormal structure: considerations in morphological responses of teleosts to pollutants. Environ Health Persp 71:139-146

Hustvedt SO, Salte R, Kvendset O, Vassvik V (1991c) Bioavailability of oxolinic acid in Atlantic salmon (Salmo salar L.) from medicated feed. Aquaculture 97:305-310

Hustvedt SO, Salte R, Vassvik V (1991a) Absorption, distribution and elimination of oxolinic acid in Atlantic salmon (Salmo salar L.) after various route of administration. Aquaculture 95:193-199

Hustvedt SO, Storebakken T, Salte R (1991b) Does oral administration of oxolinic acid or oxytetracycline affect feed intake of rainbow trout? Aquaculture 92:109-113

Jonsson HT, Walker EM, Greene WB, Hughson MD, Hennigar GR (1981) Effects of prolonged exposure to dietary DDT and PCB on rat liver morphology. Arch Environ Contam Toxicol 10:171-183

Karnovsky MJ (1971) Use of ferrocyanide-reduced osmium tetroxide in electron microscopy. J Cell Biol 51:284 (Abstr)

Klaunig JE, Lipsky MM, Trump BF, Hinton DE (1979) Biochemical and ultrastructural changes in teleost liver following subacute exposure to PCB. J Environ Pathol Toxicol 2:953-963

Kleinow KM, Jarboe HH, Shoemaker KE (1994) Comparative pharmacokinetics and bioavailability of oxolinic acid in channel catfish (Ictalurus punctatus) and rainbow trout (Oncorhynchus mykiss). Can J Fish Aquat Sci 51:1205-1211

Köhler A (1989) Regeneration of contaminant-induced liver lesions in flounder-experimental studies toward the identification of cause-effect relationship. Aquat Toxicol 14:203-232

Köhler A (1990) Identification of contaminant-induced cellular and subcellular lesions in the liver of flounder (Platichthys flesus) caught at different polluted estuaries. Aquat Toxicol 16:271-292

Le Hir M, Herzog V, Fahimi HD (1979) Cytochemical detection of catalase with 3,3'-diaminobenzidine. A quantitive reinvestigation of the optimal assay conditions. Histochemistry 51-66

Lester SM, Braunbeck TA, Teh SJ, Stegeman JJ, Miller MR, Hinton DE (1992) Immunocytochemical localization of cytochrome P4501A.1 in liver of rainbow trout (Oncorhynchus mykiss). Mar Environ Res 34:117-122

Lester SM, Braunbeck TA, Teh SJ, Stegeman JJ, Miller MR, Hinton DE (1993) Hepatic cellular distribution of cytocrome P450 IA1 in rainbow trout (Oncorhynchus mykiss): an immunohisto- and cytochemical study. Cancer Res 53 $3700-3706$

Lipsky MM, Klaunig JE, Hinton DE (1978) Comparison of polychlorinated biphenyl in liver of rat and channel catfish: a biochemical and morphological study. J Toxicol Environ Health 4:107-121

Magee PN (1966) Toxic liver necrosis. Lab lnvest 15:111-113

Meyers TR, Hendricks JR (1985) Histopathology. In: Rand GM, Petrocelli SR (eds) Fundamentals of aquatic toxicology. Taylor \& Francis, Washington, p 283-331

Nowak B (1996) Relationship between endosulfan residue level and ultrastructural changes in the liver of catfish, Tandanus tandanus. Arch Environ Contam Toxicol 30 195-202

Oshima Y, Kobayashi K, Lumbanbatu JF, Ooie K, Kawahara Y, Imada N (1994) Effect of drug-metabolizing enzyme activity induced by PCB on the duration of drugs in fish. Aquaculture (Amsterdam) 120:25-31

Oulmi Y, Negele RD, Braunbeck T (1995) Cytopathology of liver and kidney in rainbow trout Oncorhynchus mykiss after long-term exposure to sublethal concentrations of linuron. Dis Aquat Org 21:35-52

Palade GE, Schidlowsky G (1958) Functional association of mitochondria and lipide inclusions. Anat Rec 130:352

Pelosi G, Agliati G (1968) The heart muscle in functional overload and hypoxia. A biochemical and ultrastructural study. Lab Invest 18:86

Peute J, Huiskamp R, van Oordt PGWJ (1985) Quantitative analysis of estradiol-17ß-induced changes in the ultrastructure of the liver of the male zebrafish Brachydanio rerio. Cell Tissue Res 242:377-382

Phillips MJ, Poucell S, Patterson J, Valencia P (1987) The liver: an atlas and text of ultrastructural pathology. Raven Press, New York

Redshaw CJ (1995) Ecotoxicological risk assessment of chemicals used in aquaculture: a regulatory viewpoint. Aquaculture Res 26:629-637

Reynolds ES (1963) The use of lead citrate at high $\mathrm{pH}$ as an electron-opaque stain in electron microscopy. J Cell Biol $17: 208-212$

Rez G (1986) Electron microscopic approaches to environmental toxicity. Acta Biol Hung 37:31-45

Richardson KC, Jarett L, Finke EH (1960) Embedding in epoxy resins for ultrathin sectioning in electron microscopy. Stain Technol 35:313-323

Rojik I, Nemcsok J, Boross L (1983) Morphological and biochemical studies on liver, kidney and gill of fishes affected by pesticides. Acta Biol Hung 34:81-92

Samuelsen OB, Lunestad BT, Ervik A, Fjelde S (1994) Stability of antibacterial agents in an artificial marine aquaculture sediment studied under laboratory conditions. Aquaculture 126:283-290

Schoor WP, Couch JA (1979) Correlation of mixed-function oxidase activity with ultrastructural changes in the liver of a marine fish. Cancer Biochem Biophys 4:95-103

Segner H, Braunbeck T (1990) Adaptive changes of liver composition and structure in golden ide during winter acclimatization. J Exp Zool 255:171-185

Segner H, Witt U (1990) Weaning experiments with turbot (Scophthalmus maximus): electron microscopic study of liver. Mar Biol 105:353-361

Singh I (1964) A modification of the Masson-Hamperl method for staining of argentaffin cells. Anat Anz 115:81-82 
Smith JT (1985). The 4-quinolone antibacterials. In: Greenwood D, O'Grady F (eds) Progress in antimicrobial chemotherapy, Vol 38. Society for General Microblology, Symposium, Cambridge, p 69-94

Sohlberg S, AuIie A, Soli NE (1994) Temperature-dependent absorption and elimination of flumequine in rainbow trout (Oncorhynchus mykiss Walbaum) in fresh water Aquaculture 119:1-10

Spurr AR (1969) A low viscosity embedding medium for electron microscopy. J Ultrastruct Res 26:31-43

Steffenak I, Hormazabal V, Yndestad M (1994) Effect of cooking on residues of the quinolones oxolinic acid and flumequine in fish. Acta Vet Scand 35:299-301

Trump BF, Berezesky IK, Phelps PC, Jones RT (1983) An overview of the role of membranes in human disease. In: Trump BF, Laufer A, Jones RT (eds) Cellular pathobiology of human disease. Gustav Fischer, New York, p 3-48

Weibel ER (1979) Stereological methods, Vol I. Academic Press, New York

Responsible Subject Editor: D. E. Hinton, Davis, California, USA
Weibel ER, Staubli W, Gnaegi HR, Hess FA (1969) Correlated morphometric and biochemical studies on the liver cell. J Cell Biol 42:68-91

Willams MA (1977) Quantitative methods in biology. In: Glauert AM (ed) Practical methods in electron microscopy, Vol 6. Elsevier/North-Holland Biomedical Press, Amsterdam, p 5-85

Yamada T, Maita K, Nakamura J, Murakami M, Okuno Y, Hosokawa S, Matsuo M, Yamada H (1994) Carcinigenicity studies of oxolinic acid in rats and mice. Food Chem Toxi$\operatorname{col} 32: 397-408$

Yamamoto M, Egami N (1974) Sexual differences and changes in the fine structure of hepatocytes in the medaka, Oryzias latipes. J Fac Sci Univ Tokyo (Sec 4) 13:199-210

Zak R, Rabinowitz M (1973) Metabolism of the ischemic heart. Med Clin North Am 57:93

Zar JH (1984) Biostatistical analysis, 2nd edn. Prentice-Hall International, Inc, Englewood Cliffs, NJ

Manuscript first received: May 20, 1996

Revised version accepted: December 19, 1996 